\title{
A study of maternal mortality at the teaching hospital, Hubli, Karnataka
}

\author{
Sahaja Kittur* \\ Department of Obstetrics \& Gynecology, Karnataka Institute of Medical Sciences, Hubli-580022, Karnataka, India
}

Received: 13 January 2013

Accepted: 19 January 2013

*Correspondence:

Dr. Sahaja Kittur

E-mail: drsahajakittur@ rediffmail.com

\begin{abstract}
Background: Maternal mortality continues to be a major public health problem in the developing world. Maternal mortality is a vital index of the effectiveness of obstetric services prevailing in a country. The present study was conducted at Karnataka Institute of Medical Sciences, Hubli, which caters to $250 \mathrm{PHC}$ 's/CHC's and is a major referral centre for 4 districts with an average of 800-1000 deliveries per month.

Methods: Data on the maternal deaths at KIMS, Hubli from October 2010 to March 20011 during pregnancy and within 42 days of delivery of any cause, irrespective of the duration and site of pregnancy were collected.

Results: The maternal mortality ratio for the study period was per 1,00,000 live births. Among the 40 maternal deaths, 7 deaths $(17.5 \%)$ occurred in primigravida, 14 deaths $(35 \%)$ had occurred in primipara, 4 deaths (10\%) in gravida 2 and above, 7 deaths (17.5\%) in para 2, 5 deaths (12.5\%) in para 3 and 3 deaths $(7.5 \%)$ had occurred in para 4 and above. During the study period, 8 deaths (20\%) occurred within 1 hour of admission, 5 deaths (12.5\%) within 1 6 hours of admission, 7 deaths (17.5\%) between 7-12 hours of admission, 6 deaths (15\%) between 13-24 hours, 8 deaths (20\%) between 1-2 days and 6 deaths occurred after 2 days of admission. Maternal deaths had occurred mostly in delivered women (75\%) compared to undelivered women (25\%). During the study period, among the 40 maternal deaths, 34 deaths $(85 \%)$ occurred due to direct obstetric causes and 6 deaths $(15 \%)$ due to indirect causes. Among the direct obstetric causes, haemorrhage (30\%) and hypertensive disorders of pregnancy $(30 \%)$ were the leading causes. Pulmonary embolism (10\%), rupture uterus (5\%), chorioamnionitis (5\%), septic abortion (2.5\%) and acute inversion of uterus (2.5\%) were the other direct causes of maternal deaths. Among the indirect obstetric causes, 4 deaths (10\%) occurred due to anaemia which was the leading cause. One death $(2.5 \%)$ occurred due to cardiac disease and 1 death $(2.5 \%)$ due to hepatic failure.

Conclusions: Reviewing the maternal deaths that occurred in our hospital, there is an urgent need to address the issue of obstetric haemorrhages and early intervention in PIH. Much needs to be done for maternal health care in rural areas as most of the deaths reported from urban institutions are referrals from peripheral centres. Rapid transport facilities should be made available to all remote rural areas with easy accessibility. It is necessary even in urban areas to channel the working of emergency obstetric care. This prevents early intervention and adequate emergency obstetric care. The essential obstetric care for all and early detection of complications and management of emergency obstetric care services need to be seriously looked into. Most maternal deaths are preventable by health education of masses, adequate health care in the community and transport facilities.
\end{abstract}

Keywords: Maternal mortality, PPH, Preeclampsia

\section{INTRODUCTION}

Maternal mortality continues to be one of the major public health problems especially our country. Maternal mortality is a vital index of the effectiveness of obstetric services prevailing in a country. Maternal mortality is one area in Indian obstetrics where a strong concern and consensus is seen. Preeclampsia, postpartum hemorrhage and sepsis are the most important direct causes of maternal death. ${ }^{1,2}$ Anemia and jaundice are the two important indirect causes. ${ }^{1,2}$ The causes of maternal death 
in developing and developed countries are almost the same but there is a massive difference in women's chance of surviving the complications.

The important delays are in:

- $\quad$ Seeking help

- Reaching health care facility

- Diagnosis and substandard treatment and

- Arranging blood components due to lack of blood bank or lack of sufficient stock of blood products.

\section{METHODS}

\section{Source of data}

This is a clinical study of maternal deaths that occurred at Karnataka Institute of Medical Sciences, Hubli from October 2010 to March 2011.

\section{Method of collection of data}

Data on the maternal deaths that occurred at KIMS, Hubli during pregnancy and within 42 days of delivery of any cause, irrespective of the duration and site of pregnancy were collected. The deaths were classified according to WHO classification as:

1. Direct obstetric causes

2. Indirect obstetric causes

3. Non-related causes

During the present study, total births include live-births and stillbirths. Deaths due to abortions were also included, since it is one of the important causes of maternal deaths.

In the critical study of maternal mortality with regard to age, marital status, age at marriage, booked vs. unbooked, geographical location, educational status, socio-economic status, time interval since admission, mode of delivery, causes of death and various other factors have been considered.

\section{Inclusion criteria}

- All maternal deaths occurring during pregnancy and within 42 days of delivery

- $\quad$ Ectopic pregnancies

- Septic abortions

- Molar pregnancies

\section{Exclusion criteria}

- All maternal deaths occurring after 42 days of termination of pregnancy

- Accidents

\section{RESULTS}

It is noted that out of 40 maternal deaths during the study period, 17 deaths $(42.5 \%)$ have occurred in the age group of $21-25$ years. 15 deaths $(37.5 \%)$ have occurred in the age group $<20$ years of age. 7 deaths (17.5\%) have occurred in the age group of 26-30 years. 1 death $(2.5 \%)$ have occurred in the age group of $>30$ years. Age of the patients is statistically significantly associated with MMR $(p=0.001)$ (Table 1).

Table 1: MMR in relation to age of the patients.

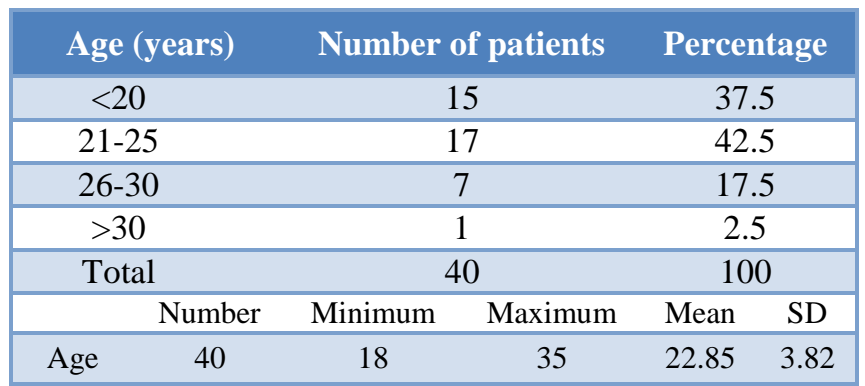

During the study period, out of the total 40 cases, 32 cases $(80 \%)$ were unhooked and 8 cases $(20 \%)$ were booked cases and is statistically significant $(p=0.0001)$ (Table 2).

Table 2: MMR in relation to booked vs. unbooked.

\begin{tabular}{|ccc|}
\hline Booked/Unbooked & $\begin{array}{c}\text { Number of } \\
\text { patients }\end{array}$ & Percentage \\
\hline Booked & 8 & 20 \\
\hline Unbooked & 32 & 80 \\
\hline Total & 40 & 100 \\
\hline
\end{tabular}

The rural population is at greater risk with regard to maternal death. During the study period, about 36 deaths $(90 \%)$ have occurred in rural population compared to 4 deaths $(10 \%)$ which have occurred in urban population. This geographical location is statistically significantly associated with MMR (p=0.0001) (Table 3).

Table 3: MMR in relation to geographical location.

\begin{tabular}{|ccc|}
\hline $\begin{array}{c}\text { Geographical } \\
\text { location }\end{array}$ & $\begin{array}{c}\text { Number of } \\
\text { patients }\end{array}$ & Percentage \\
\hline Rural & 36 & 90 \\
\hline Urban & 4 & 10 \\
\hline Total & 40 & 100 \\
\hline
\end{tabular}

It was observed from the present study that majority of maternal deaths occurred in low and middle socio economic group and it was statistically significant $(p=0.049)$ (Table 4). 
Table 4: MMR in relation to socioeconomic status.

\begin{tabular}{|ccc|}
\hline $\begin{array}{c}\text { Socioeconomic } \\
\text { status }\end{array}$ & $\begin{array}{c}\text { Number of } \\
\text { patients }\end{array}$ & Percentage \\
\hline Poor & 17 & 42.5 \\
\hline Average & 17 & 42.5 \\
\hline Good & 6 & 15 \\
\hline Total & 40 & 100 \\
\hline
\end{tabular}

It was noticed during the study period; about 14 patients (35\%) were illiterates. About 10 patients (25\%) had primary education. About 15 patients (37.5\%) had secondary schooling. Only 1 patient (2.5\%) was a graduate. Hence educational status is significantly associated with MMR and it was statistically significant $(p=0.007)$ (Table 5).

Table 5: MMR in relation to educational status.

\begin{tabular}{|ccc|}
\hline Educational status & $\begin{array}{c}\text { Number of } \\
\text { patients }\end{array}$ & Percentage \\
\hline Illiterate & 14 & 35 \\
\hline Primary & 10 & 25 \\
\hline Secondary & 15 & 37.5 \\
\hline Degree & 1 & 2.5 \\
\hline Total & 40 & 100 \\
\hline
\end{tabular}

It was observed that during the study period maternal deaths had occurred mainly in married women. No deaths had occurred in unmarried or widow, probably due to under reporting of the real picture. The average age at marriage was 18.40 years (13-27 years). During the study period, 31 deaths $(77.5 \%)$ have occurred in women who are married below 19 years of age. 7 deaths $(17.5 \%)$ have occurred in women who have married between 20 and 24 years of age. 2 deaths (5\%) have occurred in women who married after 25 years of age. Age at marriage is significantly associated with MMR and is statistically significant (Table 6).

Table 6: MMR in relation to age at marriage.

\begin{tabular}{|c|c|c|c|c|}
\hline Age (years) & $\begin{array}{r}\text { NuI } \\
\text { pa }\end{array}$ & $\begin{array}{l}\text { ber of } \\
\text { ents }\end{array}$ & \multicolumn{2}{|c|}{ Percentage } \\
\hline Upto 19 & \multicolumn{2}{|c|}{31} & \multicolumn{2}{|c|}{77.5} \\
\hline $20-24$ & \multicolumn{2}{|c|}{7} & \multicolumn{2}{|c|}{17.5} \\
\hline 25 and above & \multicolumn{2}{|c|}{2} & \multicolumn{2}{|c|}{5} \\
\hline Total & \multicolumn{2}{|c|}{40} & \multicolumn{2}{|c|}{100} \\
\hline Number & Minimum & Maximum & Mean & SD \\
\hline $\begin{array}{l}\text { Age at } \\
\text { Marriage }\end{array}$ & 13 & 27 & 18.40 & 3.2249 \\
\hline
\end{tabular}

It was noted that out of 40 deaths during the study period, 7 deaths $(17.5 \%)$ have occurred in primigravidae, 14 deaths $(35 \%)$ have occurred in primipara, 4 deaths $(10 \%)$ have occurred in gravida 2 and above, 7 deaths (17.5\%) have occurred in para 2,5 deaths $(12.5 \%)$ have occurred in para 3 and 3 deaths (7.5\%) have occurred in para 4 and above and it was not statistically significant (Figure 1).

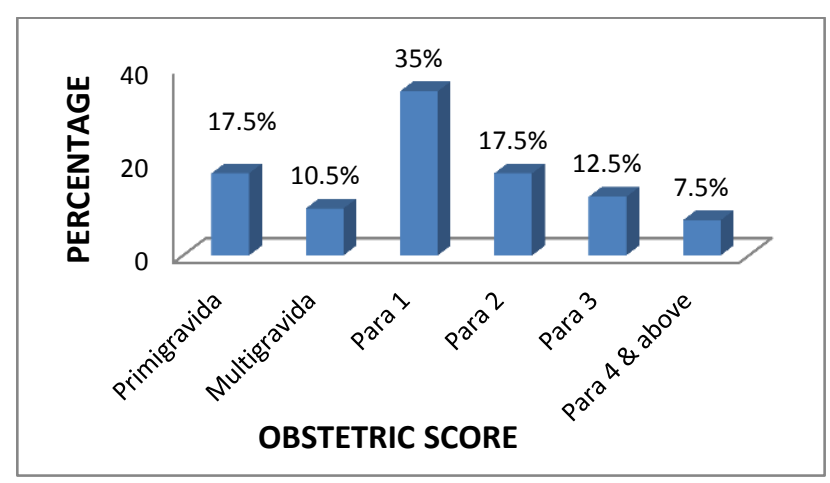

Figure 1: MMR in relation to obstetric score.

It was observed that in the present study out of 40 deaths, 8 deaths $(20 \%)$ occurred within 1 hour, 5 deaths $(12.5 \%)$ had occurred within 1-6 hours of admission, 7 deaths $(17.5 \%)$ had occurred between 7-12 hours, 6 deaths (15\%) had occurred between 13-24 hours, 8 deaths (20\%) had occurred between 25-48 hours of admission and 6 deaths $(15 \%)$ had occurred after 48 hours of admission and it was not statistically significant (Table 7).

Table 7: MMR in relation to admission-death interval.

\begin{tabular}{|cc|c|}
\hline Interval (hours) & $\begin{array}{c}\text { Number of } \\
\text { patients }\end{array}$ & Percentage \\
\hline$<1$ & 8 & 20 \\
\hline $1-6$ & 5 & 12.5 \\
\hline $7-12$ & 7 & 17.5 \\
\hline $13-24$ & 6 & 15 \\
\hline $25-48$ & 8 & 20 \\
\hline$>48$ & 6 & 15 \\
\hline Total & 40 & 100 \\
\hline
\end{tabular}

During the present study, about 30 deaths (75\%) had occurred in delivered patients and 10 deaths $(25 \%)$ had occurred in undelivered cases and it was statistically significant $(p=0.002)$.

Out of 30 delivered cases during the study period, 22 patients $(70 \%)$ had vaginal delivery. 6 women $(20.01 \%)$ underwent emergency LSCS, 1 patient (3.33\%) had molar pregnancy for which suction evacuation was done. 1 patient $(3.33 \%)$ had ventouse assisted delivery. 1 patient $(3.33 \%)$ had abortion and it was statistically significant $(p=0.0001)$ (Table 8$)$.

It was noticed from the present study, that the direct obstetric causes were responsible for 34 deaths $(85 \%)$. The indirect obstetric causes were responsible for 6 deaths $(15 \%)$ and it was statistically significant $(p=0.0001)$. 
Table 8: MMR in relation to mode of delivery.

\begin{tabular}{|ccc|}
\hline $\begin{array}{c}\text { Mode of delivery } \\
\text { Vaginal }\end{array}$ & $\begin{array}{c}\text { Number of } \\
\text { patients }\end{array}$ & \begin{tabular}{c} 
Percentage \\
\hline LSCS
\end{tabular} \\
\hline 22 & 70 \\
\hline Suction evacuation & 6 & 20.01 \\
\hline Ventouse assisted & 1 & 3.33 \\
\hline Abortion & 1 & 3.33 \\
\hline Total & 30 & 3.33 \\
\hline
\end{tabular}

It was observed that 34 deaths (85\%) occurred due to direct obstetric causes. The important direct causes were haemorrhage contributing to 12 deaths (30\%), out of which 2 deaths were due to antepartum haemorrhage, 9 deaths due to postpartum haemorrhage and 1 death was due to molar pregnancy. Hypertensive disorders of pregnancy contribute for 12 deaths (30\%). Infection including chorioamnionitis contribute to about 2 deaths (5\%) and 1 death $(2.5 \%)$ was due to septic abortion. Pulmonary embolism was the cause of death in 4 cases (10\%). 1 death $(2.5 \%)$ occurred due to acute inversion of the uterus. Among the indirect obstetric causes, anaemia was the leading cause contributing to about 4 maternal deaths. $(10 \%)$. 1 death $(2.5 \%)$ occurred due to heart disease. 1 death $(2.5 \%)$ occurred due to hepatic failure. The cause of death was statistically significant with MMR ( $\mathrm{p}=0.0001)$ (Figure 2).

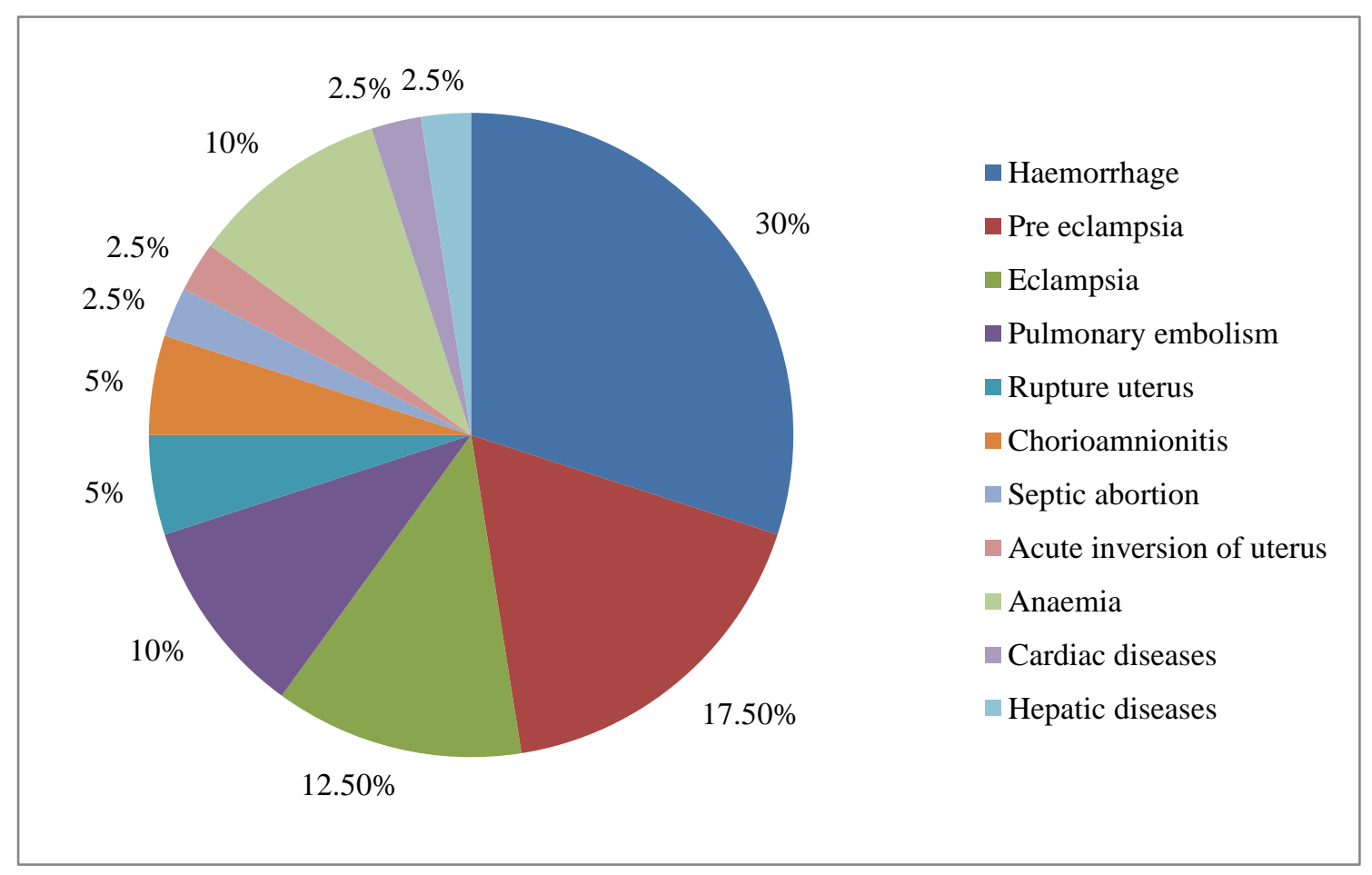

Figure 2: MMR in relation to causes of death.

\section{DISCUSSION}

During this study period from October 2010 to March 2011, 40 maternal deaths have occurred among 9,676 live-births, 62 still births, 490 intra uterine deaths and 427 abortions. Our hospital is a major tertiary referral centre for four surrounding districts which caters to more than $60 \%$ of unbooked high risk cases. In this study maternal mortality with regard to age, marital status, age at marriage, obstetric score, booked vs unbooked, rural vs urban, socio economic status, educational status, time interval since admission, mode of delivery and causes of death were critically analyzed.
Majority of maternal deaths have occurred in the age group of 21-25 years and this correlates with Surendranath Panda et al $(2000)^{3}$ and Nikhil Purandare et al (2007). ${ }^{4}$ Most of the maternal deaths were in unbooked cases and was consistent with Verma Ashok et al (2008) ${ }^{5}$ and Abha Aggarwal et al (2007). ${ }^{6}$ Regular ANCs reduce MMR.

In the present study majority of maternal deaths occurred in rural populations and this correlated with the study Verma Ashok et al (2008) ${ }^{5}$ and Jadhav AJ et al (2007). ${ }^{7}$ The rural populations are at greater risk due to poor transport facilities to reach the referral central in time. 
In the present study majority of maternal deaths occurred in low and middle socio economic status people and this correlated with Verma Ashok et al (2008). ${ }^{5}$ In our present study, educational status of women is comparatively better when compared to other studies. Majority of deaths have occurred in women who are illiterate and who had upto secondary education in contrast to Surendranath Panda et al studies where majority of maternal deaths have occurred in women who are illiterate and who had upto primary education. ${ }^{3}$ Women with education are more likely to marry later, delay child bearing, use family planning methods, seek antenatal care and make use of obstetric services available at their locality.

During the study period, majority of maternal deaths had occurred in women who had married at teen ages. This finding is consistent with the result reported by Abha Aggarwal et al (2007). ${ }^{6}$ Many of these girls have not matured properly and have smaller pelvices. Therefore the incidence of malnutrition, anaemia, pre-eclampsia, fetal mal presentations, cephalopelvic disproportion, prolonged and dystocic labours ending up in obstructed labours is higher.

In our study, majority of the deaths have occurred within 24 hours of admission which correlates with the result obtained from Surendranath Panda et al (2000). ${ }^{3}$ This is due to delayed referral resulting in late intervention and lack of qualified medical attention. This also highlights the importance of adequate and quick transport facilities.

In our study, majority of maternal deaths have occurred in women who had vaginal delivery, which correlates with the results obtained from the study of Nikhil Purandare et al (2007). ${ }^{4}$ This is because many deliveries were occurred at home and peripheral centers and referred to hospital at later stages.

The result of the present study correlates with Surendranath Panda et al (2000) and Verma Ashok et al (2008) with the direct obstetric causes contributing to the majority of maternal deaths. ${ }^{3,5}$ Our present study also correlates with WHO study ${ }^{8}$ and $\mathrm{SRS}^{2}$ in India. Because of lack of awareness, irregular ANCs and other social factors prevent women from approaching hospital.

Haemorrhage and hypertensive disorders of pregnancy are the major direct causes contributing equally to the causation of maternal mortality in our study, in contrast to Studies by Nikhil Purandare et $\mathrm{al}^{4}$, Surendranath Panda et $\mathrm{al}^{3}, \mathrm{SRS}^{2}$ and WHO studies ${ }^{8}$ where haemorrhage is the leading direct cause of maternal mortality. Most deaths in our study occurred inspite of availability of blood bank facility and availability of specialist doctors within the hospital. Although obstetric haemorrhage is vigorously tackled, the prevalence of nutritional anaemia and poor general condition failed to prevent the maternal tragedy.

In our study, anaemia is the leading indirect cause of maternal mortality which correlates with the results from
Surendranath Panda et al $(2000)^{3}$ and Verma Ashok et al (2008). ${ }^{5}$ Pre-existing anaemia worsens as pregnancy advances leading to congestive heart failure and death. It also impedes the mother's ability to resist infection or cope with haemorrhage and increases the likelihood of her dying in childbirth by a factor of four.

\section{CONCLUSIONS}

Reviewing the maternal deaths that occurred in our hospital, there is an urgent need to address the issue of obstetric haemorrhages and early intervention in PIH. Much needs to be done for maternal health care in rural areas as most of the deaths reported from urban institutions are referrals from peripheral centers. Rapid transport facilities should be made available to all remote rural areas with easy accessibility. It is necessary even in urban areas to channel the working of emergency obstetric care. Facilities in the urban hospitals are grossly inadequate with the shortage of anesthetists, pathologists and blood banks. This prevents early intervention and adequate emergency obstetric care. As well as cooperation with other departments is essential in cases of medical disorders complicating during pregnancy. The essential obstetric care for all and early detection of complications and management of emergency obstetric care services need to be seriously looked into. Post mortem examination should be conducted in all maternal deaths where the cause of death is in doubt. The public should be convinced to realize the importance of such procedure. Traditional birth attendants should be given adequate training to recognize abnormalities of pregnancy and labour since a large number of deliveries are still conducted at home in rural areas. Most maternal deaths are preventable by health education of masses, adequate health care in the community and transport facilities.

\section{Funding: No funding sources}

Competing interests: There are no competing interests to declare

Ethical approval: The study was approved by the institutional ethical committee

\section{REFERENCES}

1. Costello A, Ostin D, Manandhar D. Reducing maternal and neonatal mortality in the poorest communities. BMJ 2004;329:1166-8.

2. Registrar General of India. Maternal mortality in India: 1997-2003: trends, causes and risk factors; summary. New Delhi: Office of the Registrar General of India; 2006.

3. Panda S, Das BB, Patnaik A. An investigation into maternal mortality. Paper presented at the 44th All India Congress of Obstetricians and Gynaecologists, Ahmedabad; 28-31 December 2000.

4. Purandare N, Chandock AS, Upadhya S, Sanjanwala SM, Saraogi RM. Maternal mortality at 
a referral centre: a five year study. J Obstet Gynecol India 2007;57:248-50.

5. Verma A, Minhas S, Sood A. A study on maternal mortality. J Obstet Gynecol India 2008;58:226-9.

6. Aggarwal A, Pandey A, Bhattacharya BN. Risk Factors for maternal mortality in Delhi slums: a community based case-control study. Indian J Med Sci 2007;61:517-26.
7. Jadhav AJ, Rote PG. Maternal mortality-changing trends. J Obstet Gynaecol India 2007;57:398-400.

8. World Health Organization (WHO), authors The World Health Report 2005: Make Every Mother and Child Count. Geneva, Switzerland: WHO; 2005. Available http://www.who.int/whr/2005/whr2005_en.pdf. Accessed 9 September 2012.

DOI: $10.5455 / 2320-1770 . i j r \operatorname{cog} 20130213$

Cite this article as: Kittur S. A study of maternal mortality at the teaching hospital, Hubli, Karnataka. Int J Reprod Contracept Obstet Gynecol 2013;2:749. 